\title{
Comparative Fatigue Study of Age Hardening Al-alloys Under Residual Stress Effects
}

\author{
M. Benachour ${ }^{1, *}$, N. Benachour ${ }^{1,2}$, M. Benguediab ${ }^{3}$ \\ ${ }^{1}$ IS2M Laboratory, Mechanical Engineering, University of Tlemcen, Tlemcen, Algeria \\ ${ }^{2}$ Physics Department, University of Tlemcen, Tlemcen, Algeria \\ ${ }^{3}$ LMSR Laboratory, Department of Mechanical Engineering, University of Sidi Bel Abbes \\ *Corresponding author: bmf_12002@yahoo.fr
}

Received March 01, 2014; Revised March 24, 2014; Accepted April 11, 2014

\begin{abstract}
In this study, applied tensile plastic preload in 2024 and 7075 Al-alloys plates with central hole generate residual stress field. Around the central hole compressive residual stress was generated when finite element method was used and Von Mises criterion was applied for plastic preload. The level of compressive residual stress increase in increasing of applied plastic preload. Fatigue life and fatigue crack growth rate (FCGR) depend on the level of plastic preload. Consequently fatigue life increase and FCGR decrease. No high effect of level of applied plastic preload was shown for $7075 \mathrm{Al}$-alloy on fatigue behavior.
\end{abstract}

Keywords: Al-alloys, plastic preload, fatigue crack, compressive residual stress

Cite This Article: M. Benachour, N. Benachour, and M. Benguediab, "Comparative Fatigue Study of Age Hardening Al-alloys Under Residual Stress Effects." American Journal of Materials Science and Engineering, vol. 2, no. 1 (2014): 7-12. doi: 10.12691/ajmse-2-1-2.

\section{Introduction}

Generally, the notch could be a site of stress concentration and crack initiation. Levels of stresses generated around the notch depend on levels of applied loads. The total fatigue life depends on the presence of the residuals stresses. These residuals stresses present static load and affect the mean fatigue load (cyclic load). The residual stresses present diverse origin and several shapes [1-7]. The stress field is beneficial if the stress is in compressive state $[8,9,10,11]$. Pre-strain is a process when preload induced plastic deformation, induced intentionally or not and create a residual stress field. The level and nature of these residual stresses depend on the amplitude and direction of applied load. In the investigation of Kamel et al. [12] effects of tensile and compressive residual stress in fracture mechanics specimens by the application of a mechanical pre-load were studied using 'C' shape specimen. Finite element analysis is performed to simulate the pre-loading and the subsequent fracture loading of the cracked specimen. Recently, effect of residual stress on the fatigue behavior of 2024 Al-alloy was studied experimentally and numerically using FEM by Al-Khazraji et al. [13]. In other work, effect of residual stress induced by plastic predeformation was investigated by Jones [10] on 2024 T351 Al-alloy using four bent specimen. It was found that the fatigue life was influenced by the plastic preload. An increasing in fatigue life was shown by increasing of the level of plastic preload. The fatigue crack growth rates at low stress intensity factor were decreased by the presence of compressive residual stress. In other study conducted by Jones and Dunn [11], fatigue crack growth from a hole with residual stress introduced by pre-yielded hole was predicted using linear elastic fracture mechanics (LEFM) and the principle of superposition. Fatigue crack growth rates through a residual stress field are usually predicted using LEFM and the principle of superposition [14,15]. In the principle of superposition, stress intensity factors are determined as the sum of stress intensity factors from applied and residual stresses.

The main objective of this paper is to predict fatigue crack growth from hole for pre-yielded tensile sheet with $4 \mathrm{~mm}$ thickness using finite element method in aged hardening Al-alloys using superposition-based LEFM. The studied materials are from of family of high-strength aluminium alloys widely used in aerospace applications due to a very favourable strength-to-weight ratio. Strengthened aluminium alloys, such as those of the 2000 $\mathrm{xxx}$ and 7xxx series, exhibit, despite high tensile strength values (greater than $450 \mathrm{MPa}$ ). Additionally level of applied preload was investigated on level of residual stress distribution and fatigue crack growth of high strength $\mathrm{Al}-$ alloys 2024 and 7075.

\section{Modeeling of Residual Stress by Plastic Preload}

\subsection{Finite Element Modeling}

The FE model used in simulation of plastic preload (PP) was a plate assumed to be made from Al-alloys 7075 T6 and 2024 T351. The mechanical properties of both 
materials are shown in Table 1 . In order to analyze the respect of elasto-plastic behavior, a true stress-true strain curves as shown in Figure 1 and used as an input property of FE analysis. As shown in Figure 2, the dimensions of the plate containing $\varnothing 6$ diameter hole and thickness $(\mathrm{t})=4$ $\mathrm{mm}$.

Table 1. Mechanical properties of Al-alloys

\begin{tabular}{|c|c|c|c|c|}
\hline Al-alloys & E (GPa) & $\sigma_{Y}(\mathrm{MPa})$ & UTS (MPa) & \multirow{2}{*}{0.33} \\
\cline { 1 - 4 } 7075 T6 [16] & 70.71 & 520 & 570 & \multirow{2}{*}{0.377} \\
\hline 2024 T351[17] & 74.08 & 363 & & \\
\hline
\end{tabular}

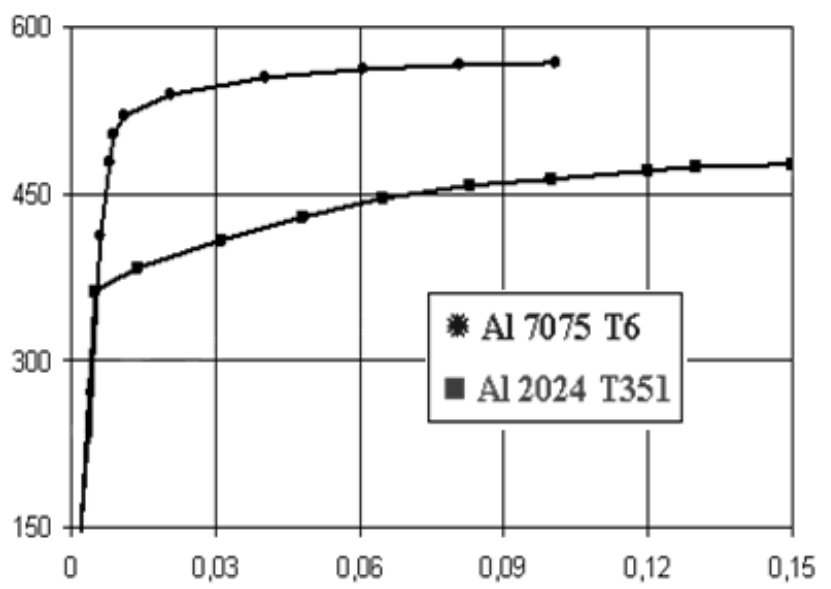

Figure 1. Trues stress-strain curves of both Al-alloys

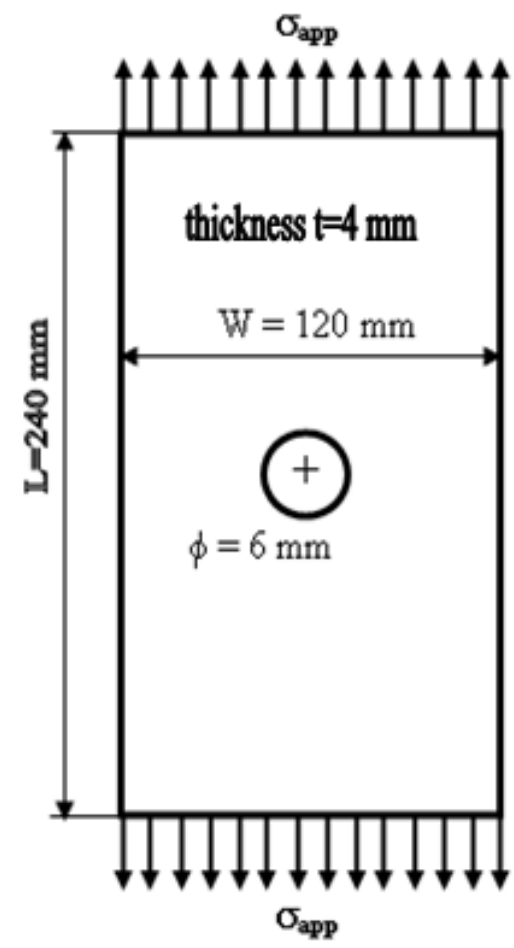

Figure 2. Sample of model analysis

Level of applied preload characterized by non dimensional ratio $\sigma_{\mathrm{p}} / \sigma_{\mathrm{Y}}$ is varied, where $\sigma_{\mathrm{p}}$ is applied plastic preload in tension and $\sigma_{\mathrm{Y}}$ is yield stress. The finite element mesh is shown in Figure 3. Only four quart of the entire plate has been modelled considering of the symmetry. More finite elements than those in other regions are put closer to the boundary of holes. Since we are interested of the residual stress variation according to the $\mathrm{X}$ axis from hole edge to free surface, two-dimensional analysis has been carried out with uniform distributed plastic preload $\sigma_{\mathrm{p}}$. The mesh element type of studied specimen is "PLANE183" implemented in finite element code ANSYS.

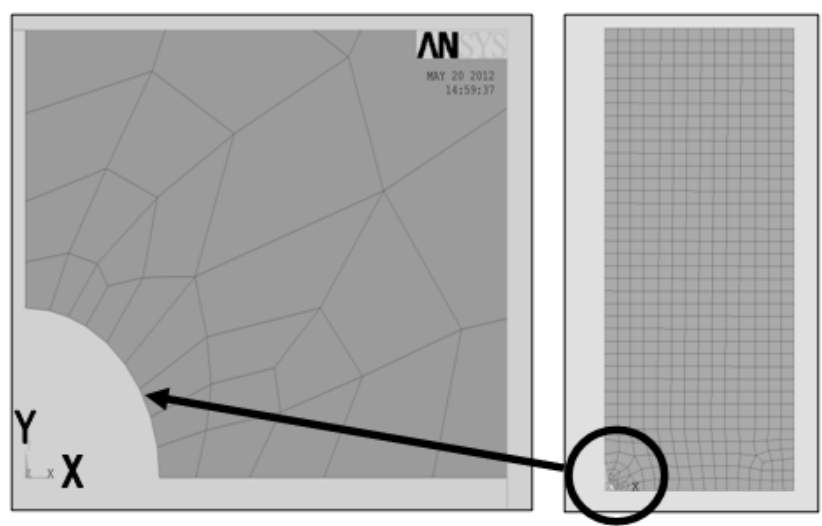

Figure 3. Quarter of FE mesh with central hole

To generate a residual stress field, the applied load must exceed the elastic limit is to say that the force generated during the loading phase of plastic deformation where the isotropic plasticity model of Von Mises was used to account of the plasticity of material. Levels of preload characterized by ratio $\sigma_{\mathrm{p}} / \sigma_{\mathrm{Y}}$ for both materials are presented in Table 2.

Table 2. Levels ratio of plastic preload

\begin{tabular}{|c|c|c|c|c|}
\hline Al-alloys & \multicolumn{4}{|c|}{$\sigma_{\mathrm{p}} / \sigma_{\mathrm{Y}}$} \\
\hline $7075 \mathrm{~T} 6$ & 1.034 & 1.077 & $/$ & $/$ \\
\hline $2024 \mathrm{~T} 351$ & 1.047 & 1.102 & 1.212 & 1.350 \\
\hline
\end{tabular}

\subsection{Residual Stress Fields}

Under applied loading levels, respective residual stress fields were generated. Figure 4 and Figure 5 shown respectively distribution of residual stress around hole $\sigma_{\text {yy }}$ for 7075 T6 and 2024 T351 Al-alloys. X-axis presents privileged path for propagating of crack. Interesting distributions of these residual stresses are along $\mathrm{X}$-axis. Distributions of residual stresses $\sigma_{y y}$ along $\mathrm{X}$-axis for 7075 T6 and 2024 T351 Al-alloys at specified preload levels are shown respectively in Figure 6 and Figure 7.

The residuals stresses distributions for two levels of plastic preload for 7075 T6 Al-alloy is given by Figure 6 . It is noticed that the variation in the level of preload does not affect the residual stress distribution (little influence), this is due to the state of the material characterized by its plastic part where the work hardening rate is very low (see Figure 2). Thereafter, the level of preload $\left(\sigma_{\mathrm{p}} / \sigma_{\mathrm{Y}}=1.034\right)$ is considered in the analysis of the fatigue behavior of this material. Figure 7 shows variation of residual stress distribution $\sigma_{\text {yy }}$ along X-axis for 2024 T351 Al-alloy at different preload levels. Residuals stresses are in compression state up to a depth of 1.57 to $1.72 \mathrm{~mm}$ from the edge of the hole. It shows an increasing of compressive residual stress with increasing of preload levels at hole. Around distance of $4.5 \mathrm{~mm}$, residual stresses become tensile stresses and difference is negligible. The residual stress in tension is maximal at 2 $\mathrm{mm}$ deep from the edge of the hole still; it is of the order of $30 \mathrm{MPa}$ for $2024 \mathrm{~T} 351$ but for 7075 T6 is also in order of $100 \mathrm{MPa}$. 

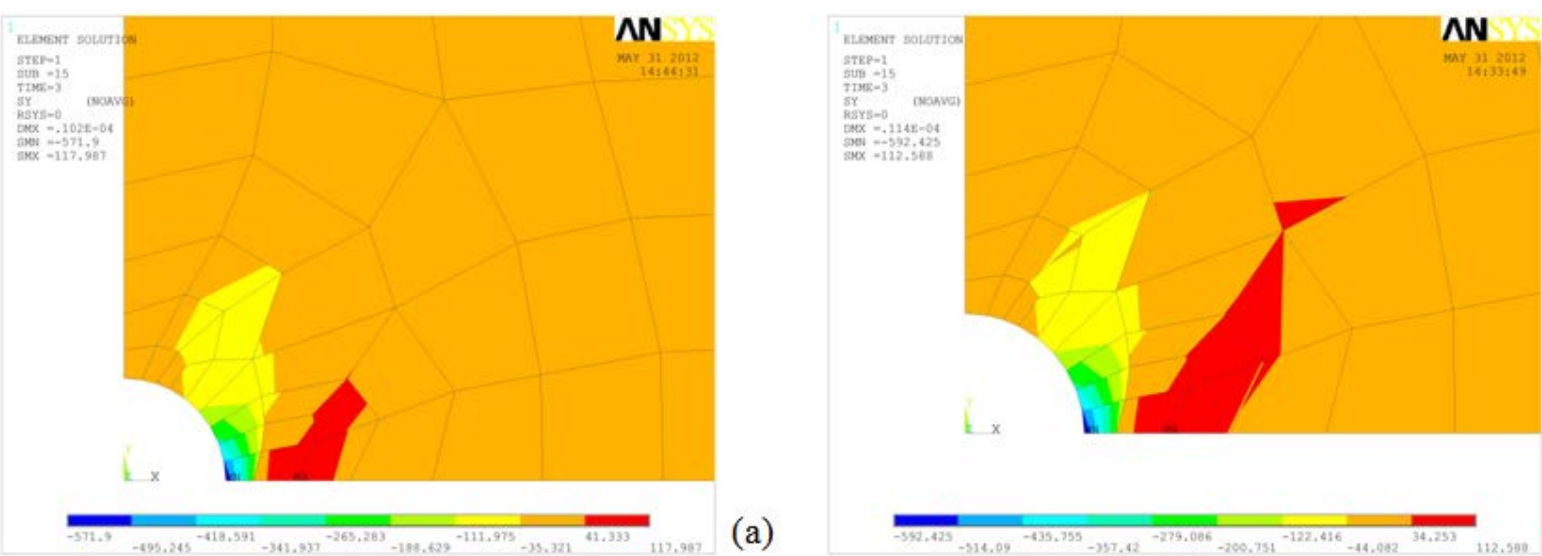

Figure 4. Stress contour for $7075 \mathrm{~T} 6$ at $\sigma_{\mathrm{p}} / \sigma_{\mathrm{Y}}$ : (a) 1.034; (b) 1.077
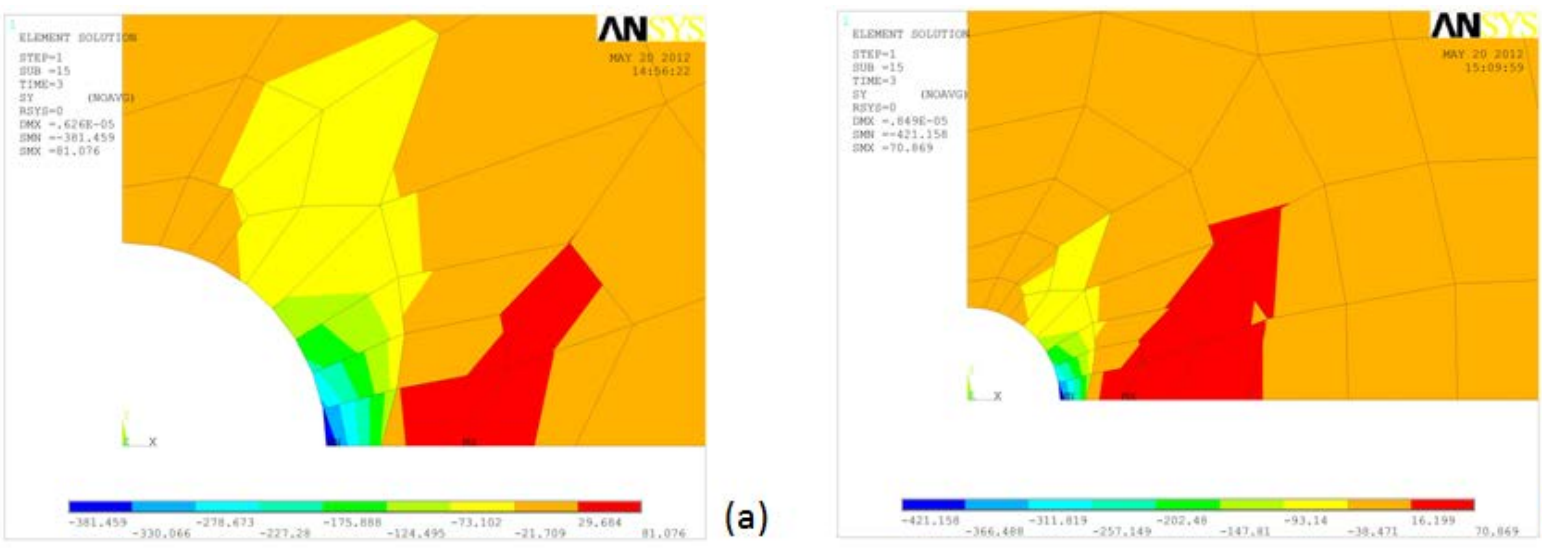

(a)

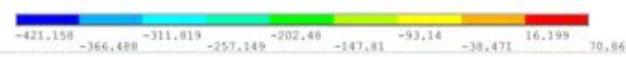

(b)
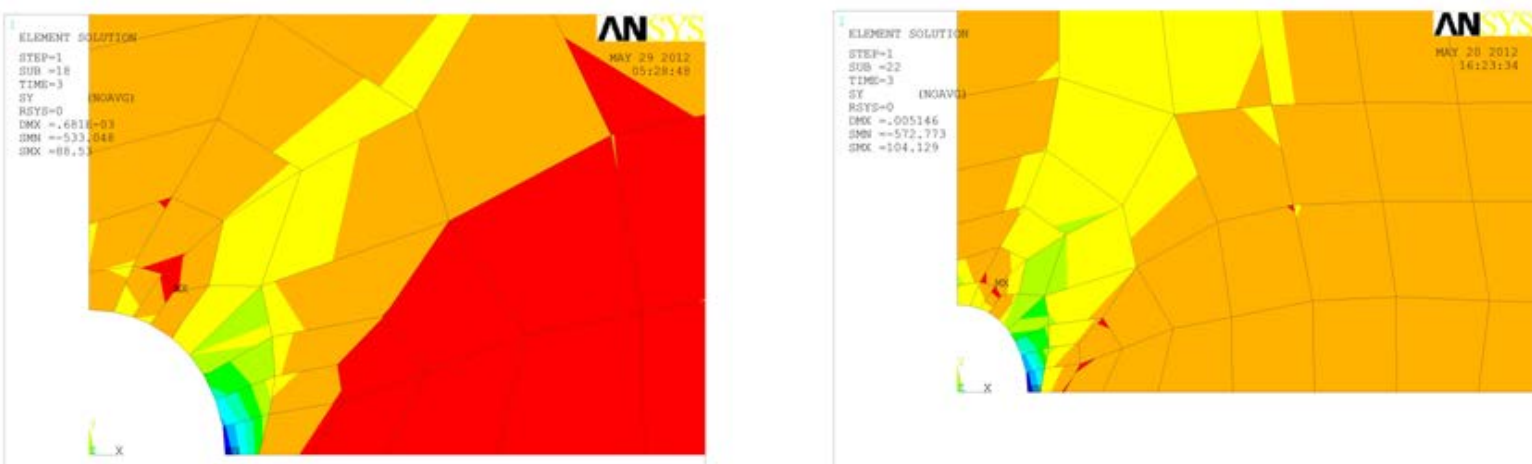

(c)

Figure 5. Stress contour for $2024 \mathrm{~T} 351$ at $\sigma_{\mathrm{p}} / \sigma_{\mathrm{Y}}$ : (a) 1.047; (b) 1.102; (c) 1.212 (d) 1.350

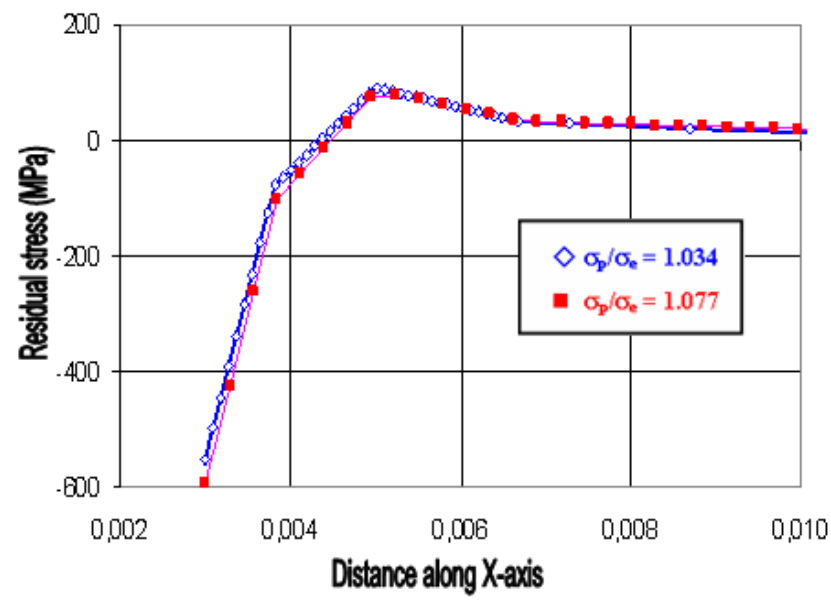

Figure 6. Residual stress along X-axis for $7075 \mathrm{~T} 6$

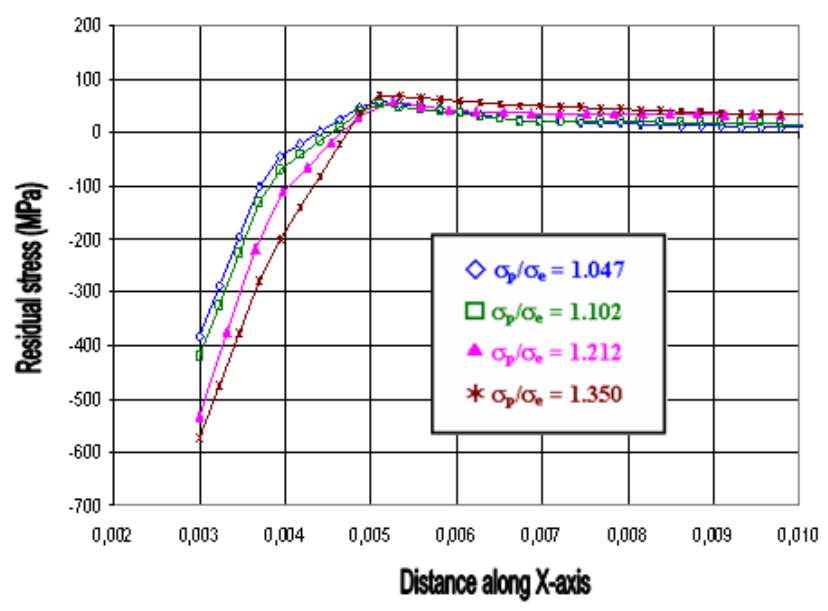

Figure 7. Residual stress along X-axis for 2024 T351 


\subsection{Fatigue Crack Growth Model}

The stress intensity factor for the studied specimen implemented in AFGROW code depends on several parameters and is given by Eq. 1 .

$$
\Delta K=\sigma \sqrt{\pi \cdot a} \cdot \beta(a / r)
$$

where $\beta$ is the geometry correction factor is expressed by (Eq. 2):

$$
\beta(a / r)=1-0.15 \lambda+3.46 \lambda^{2}-4.47 \lambda^{3}+3.52 \lambda^{4}
$$

where: $\lambda=1 /(1+(a / r))$.

In this study Forman/Mettu equation [18] was applied and then expressed bellow (Eq. 3):

$$
\frac{d a}{d N}=C\left[\left(\frac{1-f}{1-R}\right) \Delta K\right]^{n} \frac{\left(1-\frac{\Delta K_{t h}}{\Delta K}\right)^{p}}{\left(1-\frac{K_{\text {max }}}{K_{\text {crit }}}\right)^{q}}
$$

Furthers details of all parameters were detailed in AFGROW user manuals code [19]. For constant amplitude loading, the function $\mathrm{f}$ was determined by Newman [20]. Crack growth parameters of Forman/Mettu equation (Nasgro equation) for both materials are presented in Table 3.

Table 3. Parameters of Nasgro equation (Afgrow database)

\begin{tabular}{|c|c|c|c|c|c|}
\hline Al-alloys & $\mathrm{C}$ & $\mathrm{n}$ & $\mathrm{K}_{\mathrm{C}}$ & $\mathrm{p}$ & $\mathrm{q}$ \\
\hline $7075 \mathrm{~T} 6$ & $4.021 \times 10^{-10}$ & 2.95 & 59.34 & 0.5 & 1 \\
\hline $2024 \mathrm{~T} 351$ & $1.707 \times 10^{-10}$ & 3.0 & 74.72 & 0.5 & 1 \\
\hline
\end{tabular}

\section{Residual Stress Effect on FCGRs}

Figure 8 shows the evolution of FCGRs in function stress intensity factor for $7075 \mathrm{~T} 6$ Al-alloy for plastic preload $\sigma_{\mathrm{p}} / \sigma_{\mathrm{Y}}=1.034$. At a stress ratio $\mathrm{R}$ equal to 0.25 , the FCGRs increase from $4.75 \times 10^{-7} \mathrm{~m} /$ cycle to $4.23 \times 10^{-9}$ $\mathrm{m} /$ cycle with introducing compressive residuals stresses at the notch (around of the hole). The effect of stress ratio " $R$ " on the FCGRs is most striking from $\Delta K=18$ $\mathrm{MPa}(\mathrm{m})^{1 / 2}$ where the residual stresses were reduced (see distribution of residual stresses in Figure 6).

The evolution of effective stress ratio accounting of residual stress field " $\mathrm{R}_{\mathrm{eff}}$ " along the crack path is shown on Figure 9 for $\mathrm{R}=0.1$ and $\mathrm{R}=0.25$. This change in specified level of plastic preload shows that the residual stress are dominant with respect to stress ratio " $R$ " at the beginning of the cracking. From the crack length $\mathrm{a}=2 \mathrm{~mm}$, the actual stress ratio is approximately 4 . At the indicated position $(\mathrm{a}=2 \mathrm{~mm})$ residual stresses are in tensile state with maximum value of $100 \mathrm{MPa}$. Effectives stress ratios are stabilized at 0.3 and 0.11 respectively for $\mathrm{R}$ equal to 0.25 and 0.1 . Figure 8 shows also that the fatigue crack growth, for same stress ratio $(\mathrm{R}=0.25)$, an increasing in FCGR in absence of residual stress (SCR) comparatively to the FCGR with the presence of compressive residual stress at notch at same stress intensity factor rage. The difference in FCGR is in order to $2.0 \times 10^{-7} \mathrm{~m} /$ cycle.

The variation of the fatigue crack growth rates (FCGR) as a function of the amplitude of the stress intensity factor $\Delta \mathrm{K}$ through residual stresses fields obtained for different preload levels for 2024 T351 Al-alloy is shown in Figure 10. The result shows that FCGR depends on the magnitude of the compressive residual stresses developed at edge of hole. We note that the FCGR increases while decreasing the plastic preload level. At preloading level $\sigma_{\mathrm{p}} / \sigma_{\mathrm{Y}}=1.350$, FCGR is about $1.6 \times 10^{-9} \mathrm{~m} /$ cycle to crack initiation; against by a low level i.e at $\sigma_{\mathrm{p}} / \sigma_{\mathrm{Y}}=1.047$, the FCGR is $1.75 \times 10^{-7} \mathrm{~m} /$ cycle. This reduction is influenced by the decrease in residual stress intensity factor $K_{r}$ whose variation is shown on Figure 11. Factor $\mathrm{K}_{\mathrm{r}}$ past from 13.83 $\mathrm{MPa}(\mathrm{m})^{1 / 2}$ to $-4.65 \mathrm{MPa}(\mathrm{m})^{1 / 2}$.

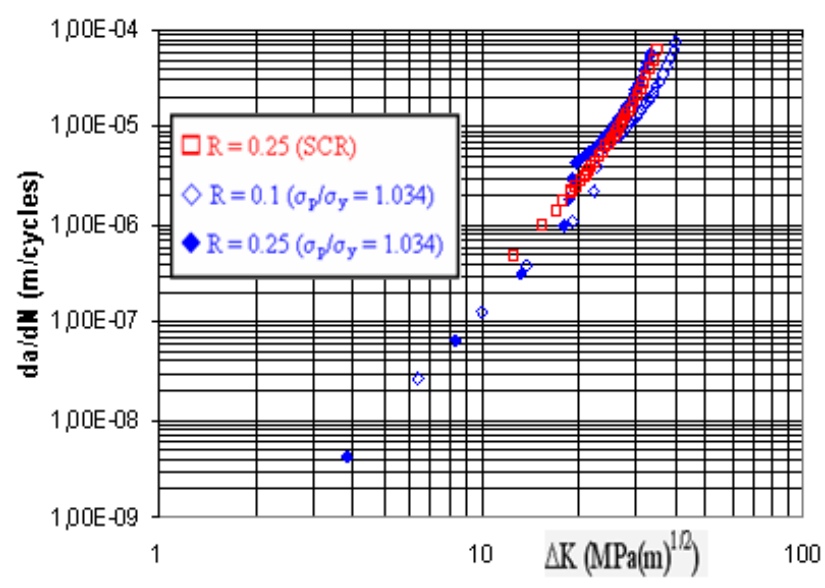

Figure 8. Effect of compressive residual stress and stress ratio on FCGRs of 7075 T6 Al-alloy

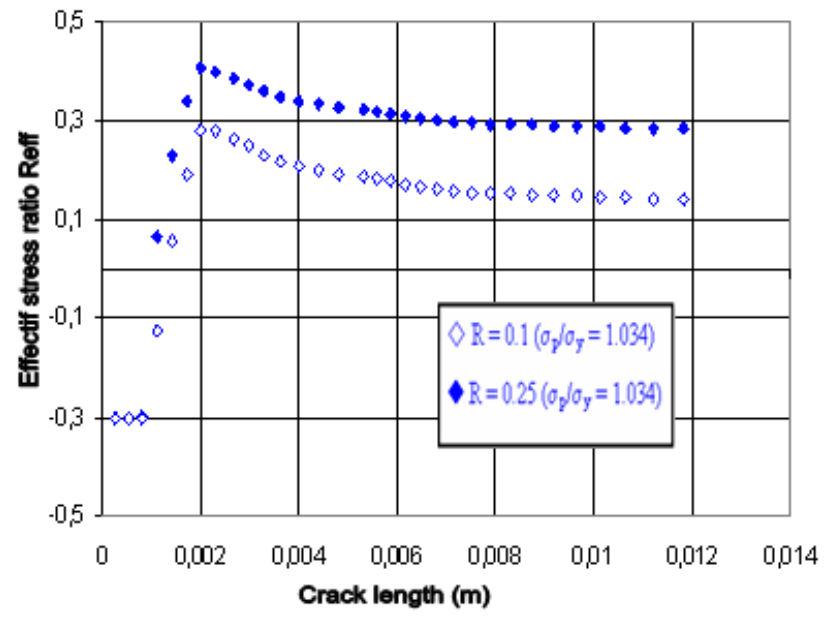

Figure 9. Plastic preload effect on stress ratio $\mathrm{R}_{\mathrm{eff}}$ for $7075 \mathrm{~T} 6 \mathrm{Al}$-alloy

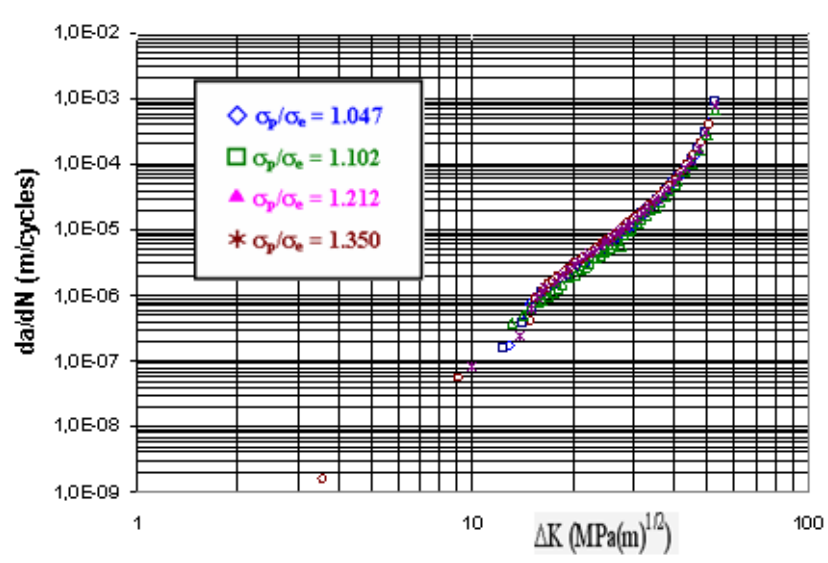

Figure 10. Plastic preload levels effect on FCGRs in 2024 T351 Al-alloy at $\mathrm{R}=0.25$ 


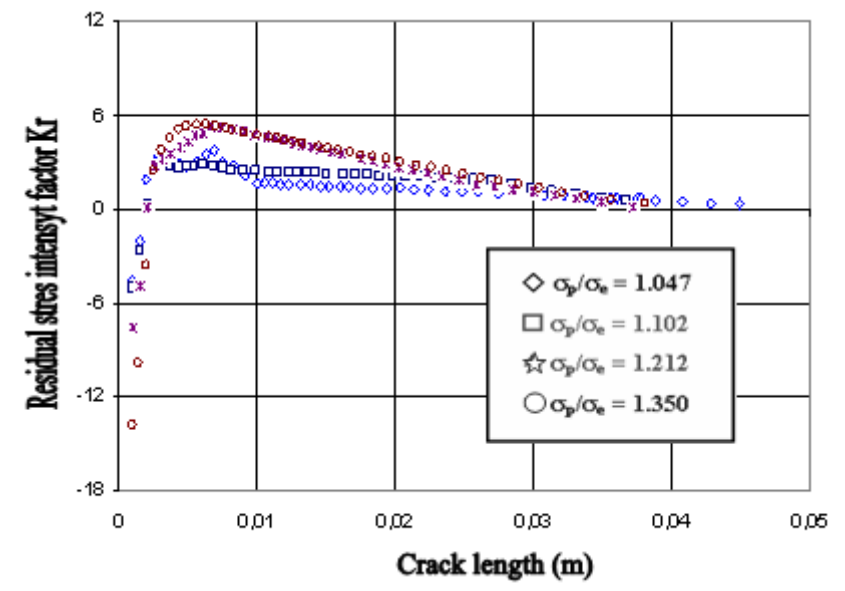

Figure 11. Effect of preload levels on residual stress intensity factor $\mathrm{Kr}$ for 2024 T351 Al-alloy

In absence of residual stress, FCGR is about $3.83 \times 10^{-7}$ $\mathrm{m} /$ cycle. The evolution of effective stress ratio during fatigue crack growth is also affect by plastic preload (Figure 12). The presence of compressive residuals stresses decrease the effective stress ratio consequently FCGRs is also decreased. Approximately at same preload for both materials and for same stress intensity factor range $\left(20 \mathrm{MPa}(\mathrm{m})^{1 / 2}\right)$, fatigue crack growth rates are respectively $2.0 \times 10^{-6} \mathrm{~m} /$ cycle and $3.0 \times 10^{-6} \mathrm{~m} /$ cycle for 7075 T6 and 2024 T351. The minimum of FCGR for 2024 T351 is around to $2.0 \times 10^{-7} \mathrm{~m} /$ cycle but for 7075 T6 FCGR is $3.0 \times 10^{-8} \mathrm{~m} /$ cycle. Comparative results show that 7075 Al-alloy present a high fatigue crack growth resistance comparatively to 2024 T351.

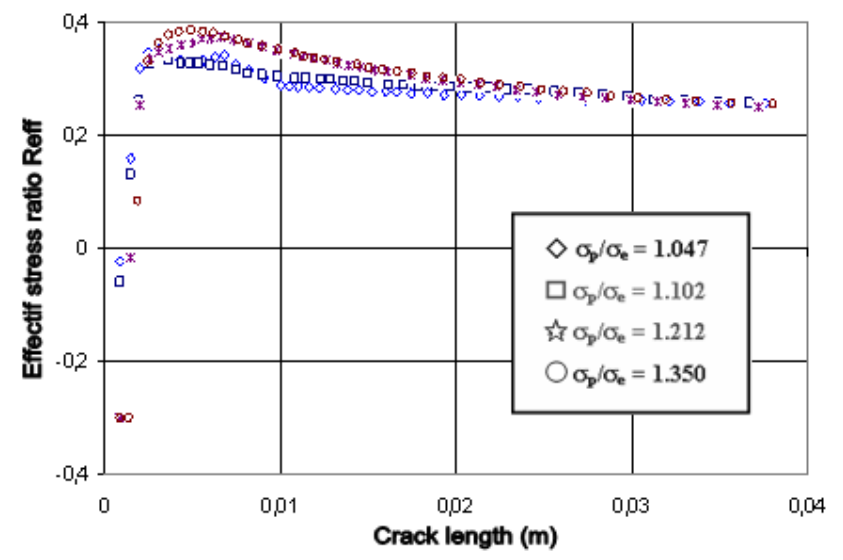

Figure 12. Plastic preload effect on stress ratio $\mathrm{R}_{\text {eff }}$ for 2024 T351 Alalloy at $\mathrm{R}=0.25$

\section{Conclusion}

Effect of compressive residual stress on fatigue crack growth rate (FCGR) behavior was investigated on two Alalloys: 7075 T6 and 2024 T351. The residuals stresses induced by plastic preload in tension were calculated numerically by finite element method (FEM). FEM computations were performed using a constitutive equation including isotropic hardening for both materials. Forman/Mettu equation was used to investigate the FCG through residuals stresses field when effective stress ratio was applied for including effects of residuals stresses. The main results of this study are:
- A decreasing in FCGR was shown in the presence of compressive residuals stresses at notch (hole).

- FCGR is affected by increasing in the level of plastic preload and depend on residual stress intensity factor witch was determined numerically.

- Aluminum alloy 7075 T6 present high fatigue crack growth rate comparatively to 2024 T351 Al-alloy.

\section{Acknowledgement}

Professor emeritus A. Pineau from Centre des Matériaux, Mines ParisTech, Evry, France is acknowledged for scientific support and fruitful discussions of residual stress effects.

\section{References}

[1] Withers, P.J., Bhadeshia H.K. "Residual stress - Part 2: Nature and Origins”, Mat. Scie. Techn., 17. 2001.

[2] Lam, Y.C. Lian, K.S., "The effect of residual stress and its redistribution on fatigue crack growth”, Theor. Appl. Fract. Mech., 12. 59-66, 1989.

[3] Pavier, M.J., Poussard, C.G.C., Smith D.J., "Effect of residual stress around cold worked holes on fracture under superimposed mechanical load”, Engineering Fracture Mechanics, 63. 751-773, 1999.

[4] Wang, H., Buchholz, F.G., Richard, H.A., Jägg, S., Scholtes, B., "Numerical and experimental analysis of residual stress for fatigue crack growth”, Computational Materials Science, 16. 104-112, 1999.

[5] John, R., Jata, K.V., Sadananda, K., "Residual stress effects on near-threshold fatigue crack growth in friction stir welds in aerospace alloy", International Journal of fatigue, 25. 939-948, 2003.

[6] Makabe, C. Purnowidodo, A., McEvily, A.J., "Effect of surface deformation and crack closure on fatigue crack propagation after overloading and under-loading”, International Journal of fatigue, 26, 1341-1348, 2004.

[7] Benedetti, M., Vigilio Fontanari, V., Bandini, M., "A simplified approach for predicting plain and notch fatigue resistance of shot peened Al-7075-T651”, Procedia Engineering, 10, 2196-2201, 2011.

[8] Beghini, M., Bertini, L., "Fatigue crack propagation through residual stress fields with closure phenomena". Engineering Fracture Mechanics, 36. 379-387, 1990.

[9] G. Gomez-Rosas, G., Rubio-Gonzalez, C., Ocan, J.L, Molpeceres, C., Porro, J.A., Chi-Moreno, W., Morales, M., "High level compressive residual stresses produced in aluminum alloys by laser shock processing”. Applied Surface Science, 252. 883-887, 2005.

[10] Jones, K.W., Dunn M.L., "Fatigue crack growth through a residual stress field introduced by plastic beam bending”. Fatigue Fracture Engineering Materials Structures, 31, 863-875, 2008.

[11] K.W. Jones, M.L. Dunn (2009). "Predicting fatigue crack growth from a preyielded hole”. International Journal of Fatigue, 31, pp 223-230.

[12] Kamel, S., Wimpory, R.C., Hofmann, M., Nikbin, K.M., O'Dowd, N.P., Advanced Materials Research, 89-91. 275, 2010.

[13] Al-Khazraji, A.N., Mohammed, F.M., Al-Taie, R.A., Eng. Tech. Journal, 29(3). 2011.

[14] Nelson, D.L. "Effects of residual stress on fatigue crack propagation”, ASTM/STP 776. 172-194, 1982.

[15] Stuart, D.H., Hill, M.R., Newman Jr., J.C. “Correlation of onedimensional fatigue crack growth at cold-expanded holes using linear fracture mechanics and superposition”. Engineering Fracture Mechanics, 78. 1389-1406, 2011.

[16] Mahmoud, S. Lease, K., "Two-dimensional and three-dimensional finite element analysis of critical crack-tip-opening angle in 2024 T351 aluminum alloy at four thicknesses". Engineering Fracture Mechanics, 71. 1379-1391, 2004.

[17] Landes, J.D., Lee, K., "Final report on computer controlled micro-indenter system”. Appendix A, The University of Tennessee Knoxvillen, Nov. 2010. 
[18] Forman, R.G, S.R Mettu, S.R., "Behavior of surface and corner cracks subjected to tensile and bending loads in Ti-6Al-4V alloy". Fracture Mechanics 22nd Symposium, Vol. 1, ASTM STP 1131, H.A. Saxena and D.L. McDowell, eds., American Society for Testing and Materials, Philadelphia, 1992.
[19] Harter, J.A., "AFGROW users guide and technical manual: AFGROW for Windows 2K/XP". Version 4.0011.14, Air Force Research Laboratory, 2006.

[20] Newman, J.C., "A Crack-Opening Stress Equation for Fatigue Crack Growth”. International Journal of Fracture, 24. R131-R135, 1984. 